\title{
Demographics, Sleep Apnea and Positive Airway Pressure (PAP) Treatment-Related Characteristics Associated with PAP Adherence: A Large Retrospective Community-Based Longitudinal Observational Study
}

Jonathan Villa

University of Ottawa

Robert Dales

University of Ottawa

Tetyana Kendzerska ( $\boldsymbol{\nabla}$ tkendzerska@toh.ca )

University of Ottawa Faculty of Medicine https://orcid.org/0000-0002-5301-1796

\section{Research Article}

Keywords: Positive airway pressure treatment, adherence, disparity, sleep apnea

Posted Date: July 16th, 2021

DOl: https://doi.org/10.21203/rs.3.rs-711393/v1

License: (c) (1) This work is licensed under a Creative Commons Attribution 4.0 International License.

Read Full License

Version of Record: A version of this preprint was published at Sleep Medicine on October 1st, 2022. See the published version at https://doi.org/10.1016/j.sleep.2022.06.017. 


\section{Abstract}

Despite many years of research, multiple factors have inconsistently shown to be associated with positive airway pressure (PAP) adherence. We conducted a retrospective observational study to evaluate the association between selected demographics, obstructive sleep apnea (OSA) - and PAP treatmentrelated factors, generally available, and objective PAP therapy adherence.

We considered all consented individuals with OSA who purchased a PAP device from a registered vendor (Ottawa, Ontario) between 2011 and 2017 who had usage data available. PAP adherence was measured objectively as PAP use for at least 4 hours on at least $70 \%$ of days on treatment. In our cohort, $7,147 / 11,634$ (61.5\%) of participants were deemed adherent to PAP. The median percentage of days PAP therapy was used was $82 \%$ (IQR: $48-97 \%$ ), and the median number of days PAP therapy was used for greater than 4 hours was 95 (IQR: 28-372).

In multivariable logistic regression considering all variables available, the effect of body mass index, age, and minimum $\mathrm{SaO}_{2}$ at baseline sleep study were significantly associated with PAP adherence.

\section{Introduction}

Worldwide, an estimated 934 million adults aged 30-69 have at least mild obstructive sleep apnea (OSA), the most common breathing disorder of sleep, with prevalence rates in some countries above $50 \%$ [1]. OSA is an important modifiable risk factor for several chronic diseases, including cardiovascular disorders [2], diabetes [3], and is associated with increased motor vehicle accidents and decreased work productivity [4]. These risks may be reduced with nightly usage of positive airway pressure (PAP) therapy, the treatment of choice for individuals with clinically significant OSA. Despite being the treatment of choice, long-term adherence to PAP is poorly investigated. Studies assessing long-term adherence in the general adult population demonstrate adherence rates between 40 to $85 \%$, depending on the definition, population and study design as clinical trials tend to overestimate the PAP adherence $[5,6,7,8,9,10,11]$. Despite many years of research, multiple factors have inconsistently shown to be associated with PAP adherence, including demographic characteristics and OSA severity $[12,13]$. Studies in the area are often limited by small numbers of participants, clinical population, and difficulty obtaining objective and longitudinal adherence data.

Our study aimed to evaluate if any treatment, demographic, or sleep apnea severity factors, generally available in clinic and research, could be used to identify individuals who were less likely to be adherent to PAP therapy. Some of the results of this study have been previously published in the form of an abstract [14].

\section{Methods}

For this retrospective community-based longitudinal observational study, all consented adults located in the greater metropolitan area of Ottawa (Canada) diagnosed with OSA by a sleep physician who 
purchased a PAP device from a provincially registered vendor between 2011 and 2017 and whose data on PAP adherence since the purchase was transferred from their devices from the AirView database (ResMed) were considered for inclusion. Information on PAP therapy type, time on therapy, demographic data, and initial OSA severity were available. In 2017, the greater metropolitan area of Ottawa had a population of 1,476,008 people and was one of the six million-plus metropolitan areas in Canada. This project has been approved by the Ottawa Health Science Network Research Ethics Board and is consistent with the principles in the Declaration of Helsinki.

Our primary outcome, adherence to PAP treatment, was defined as utilizing PAP therapy for at least 4 hours a day on at least $70 \%$ of days over time. Our secondary outcomes were: (i) the percentage of days PAP therapy was used for any amount of time and (ii) the number of days PAP therapy was used for a minimum of 4 hours. All patients were followed from the date they purchased their device through to the end of 2017.

Our factors of interest were treatment mode (Automatic Positive Airway Pressure [APAP], Bilevel Positive Airway Pressure [Bilevel], Continuous Positive Airway Pressure [CPAP]), sex, self-reported height, weight, body mass index (BMI), and baseline OSA severity. The following measures of OSA severity were considered: the apnea-hypopnea index $(\mathrm{AHI})$, or if not available respiratory disturbance index (RDI), and the minimum oxygen saturation $\left(\mathrm{SaO}_{2}\right)$.

Descriptive statistics were used as applicable to characterize our population of interest. For all outcomes, we performed both univariate and multivariate logistic or linear regressions as relevant. Beta coefficients and odds ratios were standardized using the standard deviation of the variable in question. All analyses were performed in $\mathrm{R}$ version 3.6.3. Some of the results of these studies have been previously reported in the form of an abstract [14].

\section{Results}

Of 11,614 individuals included, 6,799 (58.5\%) were male, with a median BMI of 31 (IQR: 22-40), the median age of 53 years (IQR: 34-72), the median minimum oxygen saturation of 85\% (IQR: 76-94), and the median AHI of 21/hour (IQR: 0-51); 4,542 (39.0\%) participants were on CPAP. In our cohort, 7,147 (61.5\%) participants were deemed adherent to PAP as per our primary definition. The median percentage of days PAP therapy was used was $82 \%$ (IQR: $48-97 \%$ ). The median number of days on PAP therapy regardless of usage was 130 (IQR: 47-445.75); while the median number of days PAP therapy was used for greater than 4 hours was 95 (IQR: 28-372).

For our primary outcome, using univariate logistic regression, we found increased adherence was associated with CPAP treatment mode (vs. APAP), male sex, increased weight and BMl, older age, and more severe OSA as defined by respiratory indices or minimum $\mathrm{SaO}_{2}$ (Table 1). In multivariable analysis considering all variables available, the effect of $\mathrm{BMI}$, age, and minimum $\mathrm{SaO}_{2}$ at baseline sleep study remained significantly associated with PAP adherence (Table 1). Adherence rates stratified by gender and 
age group are shown in Figure 1. For the most part, PAP adherence was higher in males than females and increases with increasing age.

For secondary outcomes, male sex, increased BMI, older age, and more severe OSA were significantly associated with a greater percentage of days participants used PAP therapy after adjusting for confounding using multivariate linear regression (Table 2). An increase in BMI and OSA severity were also significantly associated with an increased number of days participants used PAP therapy for at least 4 hours after adjusting for confounding.

\section{Discussion}

Our study is one of the larger studies investigating factors impacting PAP adherence measured objectively over a prolonged period, which importantly is also supplemented by information on OSA severity and BMI. We confirmed important differences in patterns and trajectories of PAP use by age and sex [6]. In our study, PAP adherence was generally higher in males than females and increases with increasing age. Females tend to have lower severity of OSA assessed by the AHI and female-specific symptoms [15], which may explain lower PAP adherence rates than males. Older age being a predictor of better PAP adherence, may be due to less social stigma surrounding PAP therapy because of increased incidence of OSA at higher ages [16] and increased incidence of both symptoms and comorbidities [17]. This has been documented previously [6]; however, the results were limited by a shorter time frame and individuals who required PAP adherence in order to maintain insurance coverage.

Consistent with published studies, we found increased $\mathrm{BMI}$ [18] and lower $\mathrm{SaO}_{2}$ [19] were other potential predictors of increased PAP adherence. This could be due to higher BMI's being associated with more severe and symptomatic sleep apnea [20] and an increased number of medical comorbidities [21]. PAP therapy may also be a requirement for individuals with moderate to severe OSA to qualify for bariatric surgery [22]. Oxygen saturation is also a marker of OSA severity; so, it is possible patients with lower $\mathrm{SaO}_{2}$ are more symptomatic [23] or more motivated by a sleep physician, consequently leading to greater treatment adherence.

Strengths of this study include a large sample size, an objective measure of PAP adherence, and long and complete follow-up due to remote data access. However, unmeasured confounders may bias effect estimates in this observational study as well as a limited number of characteristics available. For example, information on comorbidities and income status were not available. Other limitations include potential measurement errors and recall bias associated with self-reported height and weight and limited generalizability due to being a single-vendor study design.

Understanding factors and disparities associated with PAP adherence is essential to maximizing the benefits of PAP therapy. When prescribing PAP, we recommend using readily available variables to identify those who are less likely to use their device regularly, such as those younger, female, have a lower 
$\mathrm{BMI}$, and who have higher minimum $\mathrm{SaO}_{2}$ during the sleep study, by initiating targeted interventions to improve adherence.

\section{Declarations}

Funding: This study received funding from the Lung Health Foundation through a Team Breathe Research Award. Jonathan Villa was also supported by the Faculty of Medicine Summer Studentship Award (University of Ottawa). Tetyana Kendzerska is supported by the 2020 PSI Graham Farquharson Knowledge Translation Fellowship Award.

\section{Conflicts of interest/Competing interests: None}

Availability of data and material: The data that support the findings of this study are available from the corresponding author, TK, upon reasonable request and REB approvals.

Code Availability: Not Applicable

Author's contributions: Jonathan Villa - Study design, data analysis and interpretation, drafting the manuscript; Robert Dales - Study design, data analysis and interpretation, critically important revisions; Tetyana Kendzerska - Study conception and design, data analysis and interpretation, drafting the manuscript, critically important revisions.

All of the above authors have approved this final version of the paper to be published and agree to be accountable for all aspects of the work.

Ethic's approval: This project has been approved by both the Ottawa Health Science Network Research Ethics Board and is consistent with the principles in the Declaration of Helsinki

Consent to participate: Informed consent was obtained from all individual participants included in the study.

Consent for publication: The authors affirm that human research participants provided informed consent for publication

\section{References}

1. Benjafield A V., Ayas NT, Eastwood PR, et al (2019) Estimation of the global prevalence and burden of obstructive sleep apnoea: a literature-based analysis. Lancet Respir Med 7:687-698. https://doi.org/10.1016/S2213-2600(19)30198-5

2. Wang $X$, Ouyang $Y$, Wang $Z$, et al (2013) Obstructive sleep apnea and risk of cardiovascular disease and all-cause mortality: A meta-analysis of prospective cohort studies. Int J Cardiol 169:207-214. https://doi.org/10.1016/j.ijcard.2013.08.088 
3. Reutrakul S, Mokhlesi B (2017) Obstructive Sleep Apnea and Diabetes: A State of the Art Review. Chest 152:1070-1086

4. Allen AJMH, Bansback N, Ayas NT (2015) The effect of OSA on work disability and work-related injuries. Chest 147:1422-1428. https://doi.org/10.1378/chest.14-1949

5. Patil SP, Ayappa IA, Caples SM, et al (2019) Treatment of adult obstructive sleep apnea with positive airway pressure: An American academy of sleep medicine clinical practice guideline. J Clin Sleep Med 15:335-343. https://doi.org/10.5664/jcsm.7640

6. Rotenberg BW, Murariu D, Pang KP (2016) Trends in CPAP adherence over twenty years of data collection: A flattened curve. J Otolaryngol - Head Neck Surg 45: https://doi.org/10.1186/s40463016-0156-0

7. Campos-Rodriguez F, Martinez-Alonso M, Sanchez-de-la-Torre M, Barbe F, Spanish Sleep N. Longterm adherence to continuous positive airway pressure therapy in non-sleepy sleep apnea patients. Sleep medicine. 2016;17:1-6.

8. Kohler M, Smith D, Tippett V, Stradling JR. Predictors of long-term compliance with continuous positive airway pressure. Thorax. 2010;65(9):829-832.

9. Krieger J, Kurtz D, Petiau C, Sforza E, Trautmann D. Long-term compliance with CPAP therapy in obstructive sleep apnea patients and in snorers. Sleep. 1996;19(9 Suppl):S136-143.

10. Pepin JL, Bailly S, Rinder P, et al. CPAP Therapy Termination Rates by OSA Phenotype: A French Nationwide Database Analysis. J Clin Med. 2021;10(5)..

11. Tsuyumu M, Tsurumoto T, limura J, Nakajima T, Kojima H. Ten-year adherence to continuous positive airway pressure treatment in patients with moderate-to-severe obstructive sleep apnea. Sleep \& breathing = Schlaf \& Atmung. 2020;24(4):1565-1571.

12. Gulati A, Ali M, Davies M, et al (2017) A prospective observational study to evaluate the effect of social and personality factors on continuous positive airway pressure (CPAP) compliance in obstructive sleep apnoea syndrome. BMC Pulm Med 17:56. https://doi.org/10.1186/s12890-0170393-7

13. Mehrtash M, Bakker JP, Ayas N. Predictors of Continuous Positive Airway Pressure Adherence in Patients with Obstructive Sleep Apnea. Lung. 2019;197(2):115-121.

14. Villa J, Dales R, Kendzerska T (2020) Predictors of Adherence to Positive Airway Pressure (PAP) therapy: A Retrospective Longitudinal Observational Study [abstract]. University of Ottawa Journal of Medicine 10:S2

15. Patel SR, Bakker JP, Stitt CJ, et al (2020) Age and Sex Disparities in Adherence to CPAP. Chest 0: https://doi.org/10.1016/j.chest.2020.07.017

16. Divo MJ, Martinez CH, Mannino DM (2014) Ageing and the epidemiology of multimorbidity. Eur Respir J 44(4):1055-1068. https://doi.org/10.1183/09031936.00059814

17. Patil SP, Schneider H, Schwartz AR, Smith PL (2007) Adult obstructive sleep apnea: Pathophysiology and diagnosis. Chest 132:325-337. https://doi.org/10.1378/chest.07-0040 
18. Park P, Kim J, Song YJ, et al (2017) Influencing factors on CPAP adherence and anatomic characteristics of upper airway in OSA subjects. Med (United States) 96:

https://doi.org/10.1097/MD.0000000000008818

19. Seo MY, Lee SH (2020) Compliance with continuous positive airway pressure in patients with obstructive sleep apnea. Sleep Med. Res. 11:7-14

20. Ciavarella D, Tepedino M, Chimenti C, et al (2018) Correlation between body mass index and obstructive sleep apnea severity indexes - A retrospective study. Am J Otolaryngol - Head Neck Med Surg 39:388-391. https://doi.org/10.1016/j.amjoto.2018.03.026

21. Pantalone KM, Hobbs TM, Chagin KM, et al (2017) Prevalence and recognition of obesity and its associated comorbidities: Cross-sectional analysis of electronic health record data from a large US integrated health system. BMJ Open 7: https://doi.org/10.1136/bmjopen-2017-017583

22. Frey WC, Pilcher J (2003) Obstructive Sleep-Related Breathing Disorders in Patients Evaluated for Bariatric Surgery. Obes Surg 13:676-683. https://doi.org/10.1381/096089203322509228

23. Labarca G, Campos J, Thibaut K, et al (2019) Do T90 and SaO2 nadir identify a different phenotype in obstructive sleep apnea? Sleep Breath 23:1007-1010. https://doi.org/10.1007/s11325-01901860-0

\section{Tables}

Table 1: The association between demographics, sleep apnea- and positive airway pressure (PAP) treatment-related characteristics and whether or not a patient was considered adherent (defined as PAP therapy used $\geq 70 \%$ of days for $\geq 4$ hours) estimated using logistic regression analyses. Estimates presented as odds ratio (ORs) and $95 \%$ confidence intervals*. 


\begin{tabular}{|c|c|c|c|c|}
\hline & Univariate & & Multiva & \\
\hline & $\begin{array}{l}\text { Odds } \\
\text { Ratio }\end{array}$ & p-value & $\begin{array}{l}\text { Odds } \\
\text { Ratio }\end{array}$ & $\begin{array}{l}\mathrm{p}- \\
\text { value }\end{array}$ \\
\hline & $(95 \% \mathrm{Cl})$ & & $\begin{array}{l}(95 \% \\
\mathrm{Cl})\end{array}$ & \\
\hline Demographics at positive airway pressure (PAP) therap & tart date $(s$ & -reported) & & \\
\hline Sex: Male vs. Female & 1.13 & 0.002 & 1.10 & 0.34 \\
\hline & $\begin{array}{l}(1.05- \\
1.22)\end{array}$ & & $\begin{array}{l}(0.92- \\
1.30)\end{array}$ & \\
\hline$\uparrow$ Height $(\mathrm{m})$, per standard deviation (SD) $(11 \mathrm{~cm})$ & 0.99 & 0.80 & - & - \\
\hline & $\begin{array}{l}(0.95- \\
1.04)\end{array}$ & & & \\
\hline$\uparrow$ Weight (kg), per SD $(23.4 \mathrm{~kg})$ & 1.15 & $<0.0001$ & - & - \\
\hline & $\begin{array}{l}(1.10- \\
1.20)\end{array}$ & & & \\
\hline 个BMI, per SD $\left(7.7 \mathrm{~kg} / \mathrm{m}^{2}\right)$ & 1.17 & $<0.0001$ & 1.16 & 0.003 \\
\hline & $\begin{array}{l}(1.11- \\
1.22)\end{array}$ & & $\begin{array}{l}(1.05- \\
1.29)\end{array}$ & \\
\hline$\uparrow$ Age (years), per SD (14.3 years) & 1.33 & $<0.0001$ & 1.16 & 0.001 \\
\hline & $\begin{array}{l}(1.28- \\
1.38)\end{array}$ & & $\begin{array}{l}(1.06- \\
1.27)\end{array}$ & \\
\hline Baseline obstructive sleep apnea severity & & & & \\
\hline$\uparrow A H I$, per SD (26.2/hour) & 1.25 & $<0.0001$ & - & - \\
\hline & $\begin{array}{l}(1.17- \\
1.32)\end{array}$ & & & \\
\hline$\uparrow R D I$, per SD (22.4/hour) & 1.33 & $<0.0001$ & - & - \\
\hline & $\begin{array}{l}(1.23- \\
1.44)\end{array}$ & & & \\
\hline †Respiratory index: AHI or RDI (if AHI unavailable), per & 1.25 & $<0.0001$ & 1.075 & 0.18 \\
\hline & $\begin{array}{l}(1.18- \\
1.32)\end{array}$ & & $\begin{array}{l}(0.97- \\
1.20)\end{array}$ & \\
\hline$\uparrow$ Minimum $\mathrm{SaO}_{2}(\%)$, per SD $(7.8 \%)$ & 0.79 & $<0.0001$ & 0.89 & 0.03 \\
\hline & $\begin{array}{l}(0.73- \\
0.85)\end{array}$ & & $\begin{array}{l}(0.80- \\
0.99)\end{array}$ & \\
\hline Type of PAP treatment & & & & \\
\hline
\end{tabular}




\begin{tabular}{|c|c|c|c|c|}
\hline \multirow[t]{2}{*}{ APAP vs. CPAP } & 0.91 & \multirow[t]{2}{*}{0.02} & 0.91 & \multirow[t]{2}{*}{0.49} \\
\hline & $\begin{array}{l}(0.84- \\
0.98)\end{array}$ & & $\begin{array}{l}(0.76 \\
1.09)\end{array}$ & \\
\hline \multirow[t]{2}{*}{ Bilevel vs. CPAP } & 1.00 & \multirow[t]{2}{*}{0.97} & 1.13 & \multirow[t]{2}{*}{0.40} \\
\hline & $\begin{array}{l}(0.89- \\
1.11)\end{array}$ & & $\begin{array}{l}(0.89- \\
1.43)\end{array}$ & \\
\hline
\end{tabular}

*ORs were standardized using the standard deviation of the variable in question.

Apnea-hypopnea index, AHl; auto-titrating positive airway pressure treatment, APAP; body mass index, $\mathrm{BMl}$; confidence interval, $\mathrm{Cl}$; continuous positive airway pressure, CPAP; oxygen saturation, $\mathrm{SaO}_{2}$; respiratory disturbance index, $\mathrm{RDI}$; standard deviation, SD

Table 2: The association between demographics, sleep apnea- and positive airway pressure (PAP) treatment-related characteristics and changes in percent of days PAP was used regardless of number of hours per night (left) and number of days PAP was used a minimum of 4 hours per night (right) estimated using linear regression analyses. Estimates presented as beta coefficients and $95 \%$ confidence intervals*. 


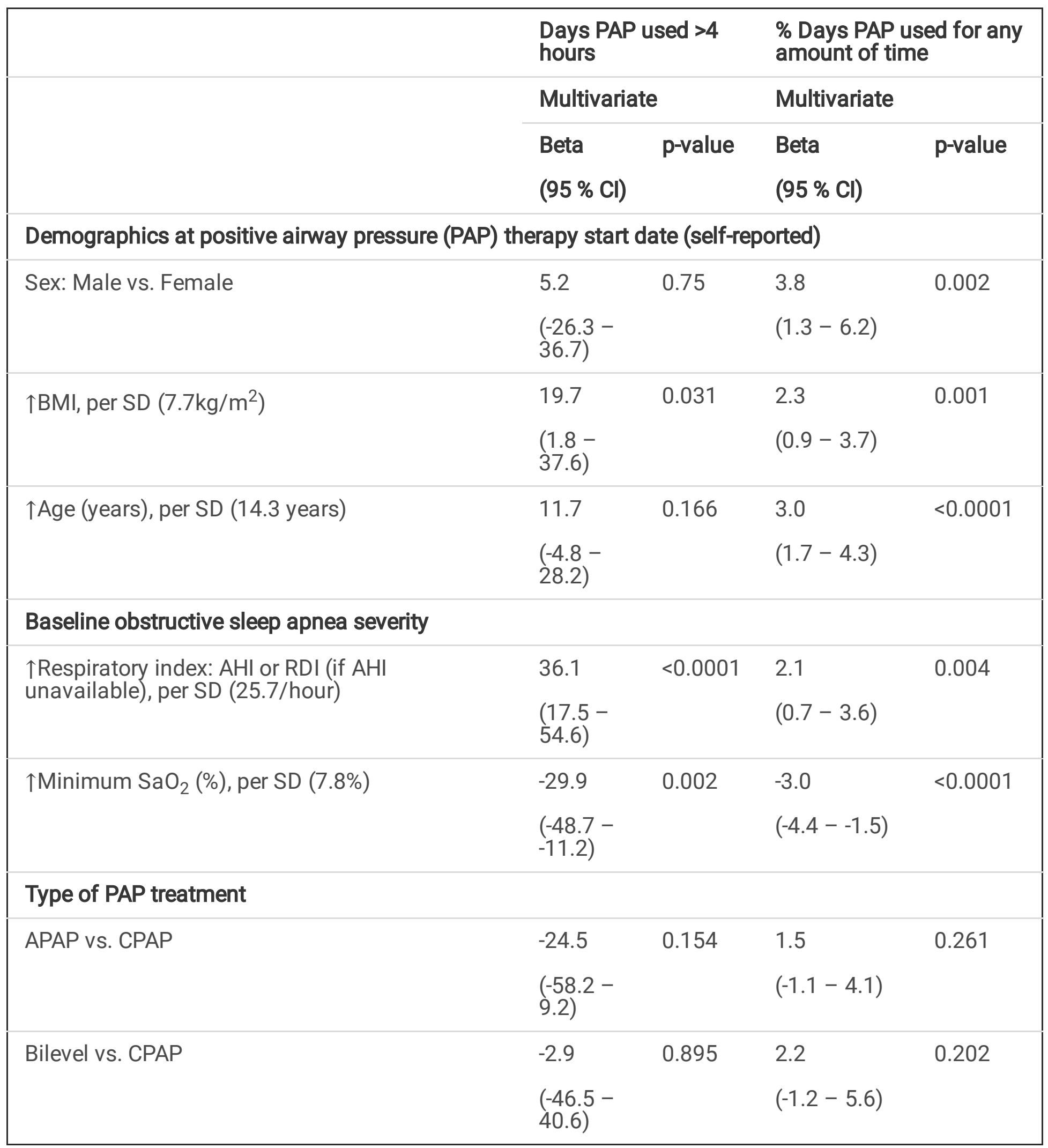

*Beta coefficients were standardized using the standard deviation of the variable in question.

Apnea-hypopnea index, AHl; auto-titrating positive airway pressure treatment, APAP; body mass index, $\mathrm{BMl}$; confidence interval, $\mathrm{Cl}$; continuous positive airway pressure, CPAP; oxygen saturation, $\mathrm{SaO}_{2}$; respiratory disturbance index, $\mathrm{RDI}$; standard deviation, SD 
Figures

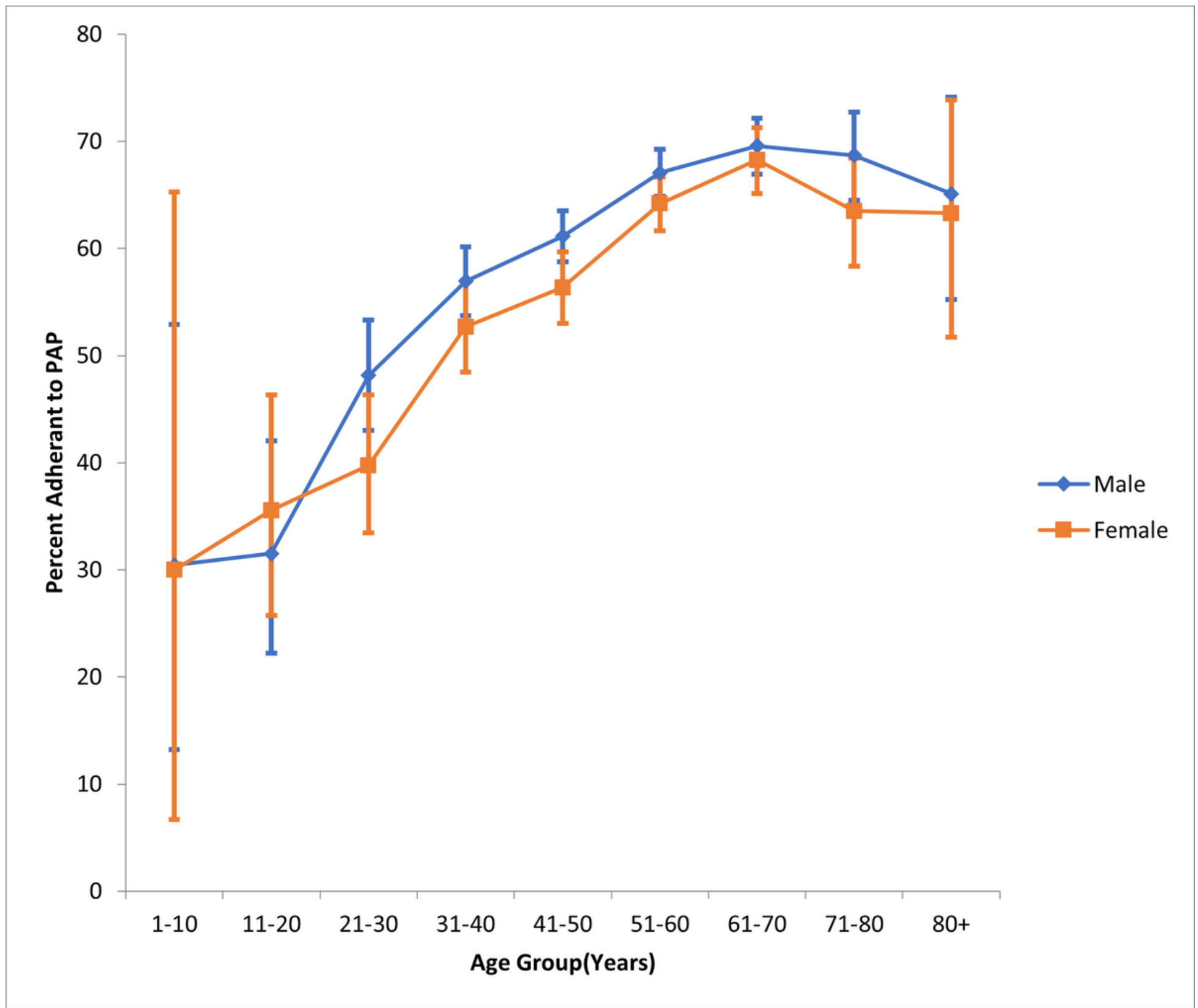

\section{Figure 1}

Positive airway pressure (PAP) adherence rates by age and gender. The proportion of patients meeting criteria for PAP adherence (4 or more hours of use per night on $70 \%$ of nights of PAP trial) by age group for males and females. Error bars display $95 \%$ confidence intervals. 